\title{
PLURALIZAR O UNIVERSAL: GUERRA E PAZ NA OBRA DE HANNAH ARENDT*
}

\author{
Verena Stolcke
}

\begin{abstract}
“O que matou os dinossauros? Perguntas enquanto cravas na minha pupila a tua pupila azul. Ou quem? Tu mesma, um meteoro, uma erupção vulcânica? M orreram apunhalados ou foram vítimas de um súbito e cal culado extermínio?" (J osé Ángel Valiente, “Anotaciones para un Fin de Siglo”, em Cabo de Gata)

“É próprio da história dos assuntos humanos que todo ato, uma vez executado e inscrito nos anais da humanidade, continue sendo uma possibilidade muito depois de sua atualidade ter passado a fazer parte da história. J amais houve castigo com suficiente poder de dissuasão para impedir que se cometam delitos." (A rendt 1999:412, tradução minha)
\end{abstract}

Durante o século XX, o poder político passa por profundas transformações. Surgem a sociedade de massas, as catástrofes totalitárias. Hannah A rendt não foi mera observadora, mas vivenciou e observou os horrores de seu tempo, o aniquilamento organizado e tecnicamente refinado dos judeus europeus, a que levou a Segunda Grande Guerra, e dedicou toda a sua vida a compreender essa "assustadora novidade", com singular paixão e autonomia de julgamento. Sua obra é, hoje, imprescindível para se refletir sobre os nossos tempos, dilacerados por guerras "locais", guerras estas inspiradas em novos - ainda que tão antigos - nacionalismos.

O pensamento de Hannah A rendt é indissociável de sua experiência pessoal enquanto judia alemã, expulsa de seu país quando Hitler chega ao poder na Alemanha, implantando a forma mais extrema do nacionalismo moderno. A própria autora assinalaria mais tarde: "não pode haver processo de pensamento que não seja o resultado de uma experiência pessoal. Todo pensamento é um 'repensar': pensa-se depois da coisa" (Gaus 1964:28).

A força motriz de Hannah Arendt foi, portanto, essa inevitável necessidade de compreender o fato inaudito e sem precedentes na história da 
humanidade do aniquilamento sistemático dos judeus europeus. Costuma-se insistir nas tensões, não resolvidas na obra de A rendt, entre liberdade e ação política. No entanto, encontrei na autora uma excepcional sensibilidade para as contradições, próprias à modernidade, entre o ideal ilustrado da dignidade humana em liberdade e as adscrições primordiais e exclusivas, assim como os engajamentos políticos convencionais. Compreender, para A rendt, significava enfrentar sem preconceitos e com atenção a própria realidade, qualquer que fosse, e resistir a ela, em vez de negar a atrocidade ou atribuí-la a precedentes históricos (Birulés 1997). Se, para compreender, é necessário evitar os preconceitos, essa compreensão tampouco pode produzir uma verdade absoluta, já que consiste em um empreendimento sempre inacabado, mediante o qual, ao estarmos submetidos a constantes mudanças, nos reconciliamos com a realidade e procuramos estar no mundo (A rendt 1953). Em lugar de esquivar-se das tensões entre liberdade e compromisso político, ou de privilegiar um lado do dilema moderno, Arendt buscou, ao longo de toda a sua vida, uma forma de conciliar a liberdade individual de movimento e pensamento com a percepção de um mundo, ao mesmo tempo, plural e compartilhado.

Duas interrogações político-morais fundamentais constituem o eixo e estabelecem uma unidade entre as análises históricas e os escritos políticos e teóricos de Arendt. Por um Iado, ela não deixa de indagar-se sobre como pode ter ocorrido algo tão inimaginavelmente assustador quanto a "fabricação sistemática de cadáveres" pelos nazistas nos campos de concentração (Gaus 1964). Esta questão fundamental, por sua vez, conduziu a autora a buscar uma resposta mais global para a seguinte pergunta: qual seria a ação política que, na sociedade moderna burocrática de massas, permitiria recuperar uma cultura cívica do público, sem que isto colocasse em jogo a liberdade e a responsabilidade individuais.

\section{A experiência do desenraizamento}

Hannah Arendt pertenceu à geração de intel ectuais judeus, pensadores que anteciparam uma crítica cultural do racionalismo moderno, proveniente da Europa Central, mas formada no seio da cultura alemã, como Franz Kafka, Walter Benjamin, Elias Canetti, Norbert Elias, Rosa Luxemburgo, e que, à exceção de Kafka, vivenciaram, como ela, o desterro, ou pereceram, vítimas do regime nazista 1 .

Hannah Arendt cresceu sem ter consciência do crescente clima antisemita da Alemanha. Nasceu em 1906, em Linden, próximo a Hannover, 
na Alemanha guilhermina. Educada em Königsberg, cidade de Kant, a quem leu ainda adolescente, foi filha única de Paul e Martha (Cohn) A rendt, ambos procedentes de antigas famílias judias russas de empresários, abastadas, assimiladas e liberais. Seu avô paterno fora presidente da municipalidade liberal de Königsberg. A os sete anos, seu pai, um engenheiro, morre de sífilis. Sua mãe, que se casou novamente em 1920 e era simpatizante do movimento social-democrata, protege Arendt, durante a infância, do difuso anti-semitismo, fomentando nela um saudável senso de dignidade pessoal (Gaus 1964). Em 1924, A rendt inicia seus estudos de teologia e filosofia na Universidade de M arburgo, onde conhece o jovem filósofo Heidegger, ainda que essa relação tenha sido interrompida por sua mudança para Freiburg, e depois para a Universidade de Heidelberg, onde vai estudar com Karl J aspers, o psicólogo convertido à filosofia, com quem Heidegger desenvolvia uma filosofia da existência: a indagação sobre como os seres humanos chegam à - ou fracassam na - realização de suas possibilidades humanas (Young-Bruehl 1993:98-ss.). Com J aspers, Arendt conclui sua dissertação sobre “A idéia do amor em Santo Agostinho"2.

Sua sensibilidade para o judaísmo e o modo de entender sua própria identidade judia passam por uma profunda transformação na cidade de Berlim, para onde se muda em 1929, casando-se com o filósofo judeu Günther Stern (antes Anders), enquanto o anti-semitismo se vai tornando abertamente hostil. A rendt começa a duvidar da assimilação enquanto possibilidade real para os judeus alemães, diante dos altos custos psicológicos que comporta. Como ela constata, não resta aos judeus assimilados sequer a opção de serem párias ou parvenus, frágeis adventícios ( $M$ ommsen 1986). A o reconhecer a impossibilidade da assimilação da condição judia à cultura alemã, ela se distancia progressivamente dos ideais ilustrados igualitários e humanistas (Benhabib 1993).

A rendt plasma suas inquietudes sobre o dilema da identidade dos judeus alemães em um estudo de extraordinária sensibilidade e empatia, no qual retrata as vicissitudes sociais e emocionais de que padeceu a célebre escritora romântica judia Rahel Varnhagen, e seu salão berlinês. Desde seus tempos de estudante em Heidelberg, Arendt interessava-se pelo romantismo alemão e pelos salões judeus, onde os românticos alemães costumavam reunir-se no final do século XVIII. Também em Heidelberg, ela conhecera Karl Blumenfeld, líder sionista alemão, que a iniciou na "questão judia", fomentando nela a consciência de sua identidade judia3. Em Berlim, Arendt articula ambos os fios temáticos, o romantismo e a questão judia, através de pesquisa biográfica sobre a escritora Rahel 
Varnhagen (A rendt 1958a). A partir do relato da excêntrica e exposta vida escolhida por Rahel Varnhagen em sua incessante busca pela assimilação à boa sociedade aristocrática prussiana - condenada irremediavelmente a amargos fracassos -, A rendt dá início à reflexão sobre sua própria condição de Aussenseiterin (pessoa estranha, não-pertinente, fora de lugar), de pária, como ela denominaria. M ostra, ainda, como o fato de ser mulher limitava as possibilidades de aceitação social de Rahel Varnhagen. Não existia para ela outra via, senão o casamento com um aristocrata alemão, para despojar-se de sua procedência judia4.

A biografia de Rahel Varnhagen, que apresenta traços quase autobiográficos, é premonitória da trajetória de vida de Arendt, exceto em um aspecto crucial: ela não cometerá o mesmo erro de sua protagonista de investir esforços na busca pela assimilação. Ao contrário, sempre optará, de modo irrevogável, pela liberdade de pária, própria às pessoas não assimiladas. Segundo Arendt, os verdadeiros seres humanos, autenticamente livres, são os/as párias (Young-Bruehl 1993).

Quando, na Alemanha de 1933, Hitler chega ao poder e ocorre o incêndio do Reichstag, seguido de uma onda de prisões "preventivas" pela Gestapo (a polícia secreta do Estado), Hannah A rendt decide-se, pela primeira e única vez, pelo ativismo político. Sente-se responsável!, como explicará mais tarde (Gaus 1964). A rendt oferece seus serviços à Organização Sionista Alemã através de Karl Blumenfeld, seu presidente. A decisão é, antes de tudo, política, mais do que o resultado de uma inquietação pessoal enquanto judia alemã, provocada pelas circunstâncias políticas vigentes: "Quando nos atacam como judeus, temos que defender-nos como judeus" (Gaus 1964). A rendt insiste na distinção entre o compromisso político e a identidade pessoal. Não cabia reduzir a "existência judia" a um problema pessoal nem, portanto, pretender solucionálo no plano individual. O que estava em jogo era uma questão eminentemente pública e, como tal, política. Uma opção pessoal, como aquela adotada por Rahel Varnhagen, teria significado, pelo contrário, ignorar as importantes diferenças sociopolíticas entre os próprios judeus europeus - desobrigando-se, portanto, do destino dos judeus não assimilados de classe baixa -, assim como tolerar o anti-semitismo, ao curvar-se perante ele na tentativa de livrar-se da condição de judia.

M as a distinção de A rendt entre a liberdade pessoal, como ser humano singular que reivindica, e a responsabilidade política que professava como judia, não estava isenta de dificuldades conceituais e políticas, características dos movimentos coletivos de resistência que lutam contra formas de opressão fundadas em exclusões atribuídas a diferenças essen- 
ciais organizadas em função desses mesmos critérios de exclusão. O compromisso político de Arendt, em última instância, surgia de sua condição de judia, dada por nascimento, mesmo que ela jamais tivesse aceitado esta condição de origem como determinante de sua responsabilidade enquanto indivíduo.

A rendt nunca conseguirá resolver esta tensão entre o vir a ser judia em razão de circunstâncias políticas e o compromisso com a causa judaica por ser judia. Sua postura com relação à existência dos judeus, enquanto povo, será sempre reservada e ambígua. Como assinalará nos anos 60, quando jovem ela nunca se sentira alemã, enquanto pertencente a um povo, e sim como parte de um Estado alemão (Gaus 1964). E em resposta a uma crítica de J aspers, segundo a qual, em uma palestra sobre Varnhagen, ela "objetivizava" a "existência judaica" que ele, fiel ao pensamento existencialista, entendia como um fenômeno puramente contingente, acidental, uma mera "forma de falar", A rendt afirmou que, enquanto a "existência judaica", por um lado, se tinha transformado para ela em uma questão política em virtude da perseguição aos judeus e ao fato de os intelectuais alemães, muitos deles seus amigos, alinharem-se ao regime nazista, por outro, o ser judia, mais do que um acidente, era uma forma de destino (Schicksalshaftigkeit) que ela assumia, não como simples reconhecimento, mas enquanto pária, como um desafio (Benhabib 1993; Gaus 1964; M ommsen 1986). Seu Bodenlosigkeit (desenraizamento) constituirá, para Arendt, um requisito indispensável para a independência de julgamento, ainda que jamais deixe de identificar-se com o destino do povo judeu e de reconhecer sua própria procedência judia. No entanto, ela nunca se conceberá como sionista e jamais abandonará o ceticismo que Ihe inspira a idéia de uma cultura nacional judaica e a criação de um Estado judeu. Como afirmaria, em 1958, em uma carta enviada dos Estados Unidos a J aspers: "O Fremdheit (estranhamento) e o Bodenlosigkeit (desenraizamento), se bem entendidos, facilitam a vida em nossos tempos [...]. Nada nos aproxima excessivamente; é como uma pele que vai se fechando de fora pra dentro. Desse modo, é possível permitir-se de novo continuar sendo sensível e vulnerável" (apud Nordmann 1993:91).

No verão de 1930, A rendt se vê obrigada a abandonar Berlim. A Organização Sionista A lemã encarregara-Ihe de compilar a Greuelpropaganda (as difamações anti-semitas de organizações proletárias alemãs em revistas profissionais e outros veículos) para denunciar, no plano internacional, os métodos que o regime nazista empregava para perseguir os judeus. Acaba sendo detida pela Gestapo (Gaus 1964), mas consegue escapar, refugiando-se em Paris, onde permanece até 1940, momento em 
que o exército alemão invade a França, trabalhando para organizações sionistas e no resgate de crianças judias do Terceiro Reich levadas à Palestina.

Em Paris, inicia sua amizade com Walter Benjamin, a personificação dessa segurança sonâmbula característica do pária, cujo ceticismo em face de todas as tradições culturais e convenções sociais dota-Ihe de uma especial habilidade para perceber as falsidades das identidades sociais. Arendt conhece também Heinrich Blücher, procedente de Berlim, membro refugiado da Liga Espartaquista de Rosa Luxemburgo e filósofo autodidata, com quem se casa em 1940, poucos meses antes da entrada do exército alemão na França.

A minúscula moradia de Benjamin em Paris converte-se em um ponto de encontro de um pequeno grupo de intelectuais refugiados para discussões políticas; Blücher estava entre eles. A partir dessas intensas discussões políticas e intelectuais e de seu estudo dos escritos do dreyfusard judeu-francês Bernard Lazare, Arendt consolida uma concepção política da complexa figura do/a pária, que transcende agora a experiência existencial de Aussenseiterin, transformando-se de um requisito para a liberdade de movimento em uma exigência ineludível da liberdade individual de pensamento. A autenticidade humana da figura de pária reside na sua habilidade em unir o julgamento independente à responsabilidade política, em contraste ao parvenu, ao adventício, dominado por suas ambições sociais (Nordmann 1993:71-72; Young-Bruehl 1993:169).

A estada em Paris é abruptamente interrompida em maio de 1940. Arendt é detida pelas autoridades francesas como "estrangeira inimiga" e enviada, junto com outros refugiados procedentes da Alemanha, ao campo de internamento de Gurs, nos Pirineus, triste lembrança na memória dos refugiados da Guerra Civil espanhola. Como ela ironizaria, “[...] a história contemporânea criara um novo gênero de seres humanos: aqueles que tinham sido levados aos campos de concentração por seus inimigos e aqueles levados aos campos de internamento por seus amigos" (Arendt 1993). Por sorte, o caos provocado pela entrada do exército alemão na França permite-Ihe novamente fugir e reencontrar seu marido, com quem, em maio de 1941, empreende o caminho para o exílio nos Estados Unidos.

Hannah A rendt chega aos Estados Unidos como apátrida, como pessoa despojada de sua Heimat (pátria) — recebe a nacionalidade norte-americana apenas em 1951. Ali, compartilha o destino de muitos intelectuais europeus refugiados, geralmente acolhidos com pouco entusiasmo no país. Os primeiros anos de exílio são duros. Sua consciência de Aussenseiterin torna-se mais profunda. Seu extraordinário dom para congregar pessoas faz com que o casal Arendt-Blücher seja rapidamente rodeado por um 
grupo de intelectuais de esquerda e amigos fiéis. No entanto, suas relações com as organizações e com a comunidade judaica são ambivalentes5.

\section{0 assustadoramente novo}

O golpe emocional e político mais duro, no entanto, estaria ainda por vir. As primeiras notícias de Auschwitz chegam em 1943. A inconcebível brutalidade das "fábricas de extermínio", carente de qualquer lógica ou necessidade militar, mergulha A rendt em uma profunda melancolia diante desse testemunho extremo e sem precedentes de como o ser humano pode ser reduzido a um mero feixe de reações e ter sua vontade, personalidade e liberdade completamente anuladas, em rompimento radical com a tradição moral e cultural do Ocidente. Auschwitz nunca deveria ter ocorrido! (Gaus 1964; A rendt e Blumenfeld 1995:43).

No fim da guerra, A rendt encontra-se trabalhando no seu célebre estudo sobre as origens do totalitarismo, no qual tenta compreender as raízes e circunstâncias políticas que tornaram possível a assustadora novidade do extermínio dos judeus europeus. A obra completa As Origens do Totalitarismo é publicada em 1951. O livro proporciona-Ihe seu primeiro reconhecimento público enquanto intelectual pela imediata controvérsia que provoca (Arendt 1999). Arendt iniciara sua análise do totalitarismo em um clima de desespero absoluto e o tinha concluído em meio a um otimismo desmedido, suscitado pela vitória sobre o fascismo. Não obstante, ela conseguiu superar, tanto o profundo desalento da guerra, quanto as ingênuas ilusões de uma paz eterna no pós-guerra.

As Origens do Totalitarismo suscitou severas críticas, em especial pelo paralelismo que A rendt detectou entre o totalitarismo nacionalsocialista e o stalinismo, bem como por algumas simplificações históricas. Os críticos de esquerda pouco compreenderam o efeito político que o pacto de não-agressão entre Hitler e Stalin tivera para os judeus alemães na desqualificação do projeto comunista (Benjamin 2000; Klemperer 1995).

Em As Origens do Totalitarismo, Arendt desafia as interpretações convencionais sobre o extermínio dos judeus europeus'. Para ela, a "solução final" - o aniquilamento dos judeus - idealizada e executada com inenarrável crueldade e eficácia pelo regime nacional-socialista alemão, ainda que sem precedentes, não foi historicamente inevitável, nem constituiu um fenômeno excepcional (Sonderfall) no mundo moderno. Enquanto protótipo da total privação de direitos a uma população, esse episódio encontrava antecedentes no "assassinato administrativo" praticado pelo 
imperialismo colonial europeu. O "assustadoramente novo" na eliminação física sistemática de milhões de prisioneiros - homens, mul heres e crianças judias e outros grupos humanos declarados inimigos da nação alemã e internados nos campos de concentração pelo regime nazista estava na verdade na sua prolixa execução burocrática e tecnificada, desprovida de toda dimensão moral. Para esse caráter amoral do holocausto, contribuiu o avanço da técnica que permitiu matar à distância, em flagrante ruptura com a história européia (Gaus 1964; Arendt 1967 [1951]; 1999; Whitfield 1998).

A lém disso, o extermínio dos judeus também não foi, para Arendt, produto de um "anti-semitismo eterno", nem radicava em algum "fato" diferencial das vítimas. $\mathrm{O}$ que tornou possível o holocausto foram as novas circunstâncias sociopolíticas e ideológicas que acompanharam a formação do Estado nacional moderno no século XIX, e que deram origem a uma sociedade progressivamente atomizada e burocratizada, favorecendo 0 abandono das massas a estreitas satisfações pessoais e a manipulações políticas. $O$ ódio de outrora aos judeus, de cunho religioso, tinha se transformado de modo radical ao longo do século XIX, convertendo-se, no século XX, em uma forma extrema de nacionalismo que respondia a uma necessidade interna ao regime totalitário de forjar uma imagem inimiga ameaçadora. A rendt não se serve do argumento, tão acionado na atualidade, de uma suposta propensão do ser humano à rejeição do estranho, em vez disso, desenvolve uma lúcida análise crítica da lógica exclusivista do próprio Estado nacional moderno. Os judeus, como também os ciganos, prestavam-se à encarnação dessa ficção de inimigos por jamais se terem integrado plenamente à nação. A rendt nega a existência de um conflito de interesses econômi cos entre a maioria alemã e a minoria judia, como argumento de causalidade para explicar a perseguição destes últimos. Pelo contrário, os judeus assimilados, ao batizarem-se por não aceitarem sua condição judia, tinham contribuído para que seu antigo "crime" religioso de ser judeu se transformasse em um "vício" inerente, que somente poderia ser extirpado mediante seu aniquilamento. Um antecedente dos campos de morte foi a esterilização ou o assassinato de alemães "defeituosos" em câmaras de gás. Para poder levar a cabo a eliminação física dos judeus alemães e daqueles resi dentes nos territórios incorporados ao Reich, de acordo com sua lógica nacionalista, o regime totalitário teve, antes de tudo, de "diferenciar" a minoria perseguida, negando-Ihe sua condição de sujeitos de direitos, privando-os de sua nacionalidade e convertendo-os, assim, em apátridas que, como a própria Arendt, tinham perdido seu Heimat. 
A inda que Arendt supusesse que a consolidação da sociedade de massas ocorreria acompanhada da desagregação do Estado nacional, e não levasse sua tese do caráter nacionalista do anti-semitismo moderno até as últimas conseqüências - elaborando uma crítica ao Estado nacional moderno exclusivo que funda a igual dade formal de direitos na uniformidade cultural, racial e institucional de seus cidadãos -, é inegável a absoluta atualidade de sua obra em face do alarmante ressurgimento do nacionalismo contemporâneo e das guerras genocidas, do caráter insolúvel do conflito palestino e do colapso do império soviético. Ainda assim, a desilusão que sentiu com o fracasso da idéia de um Estado binacional palestino no Oriente M édio, quando foi criado o Estado de Israel em 1948, distanciou-a ainda mais da comunidade judaica organizada que, a partir daquele momento, concentrou seus esforços na soberania judaica sobre a Palestina.

Quando A rendt retorna à A lemanha pela primeira vez, em 1949, percorre durante seis meses um país devastado e constata, com pessimismo talvez excessivo, que os alemães tinham "perdido o sentido de realidade", tendo em vista a profunda perturbação moral que reinava, manifestada em um silêncio quase absoluto sobre o terror nacional-socialista (Arendt 1993). Como ela assinalaria anos mais tarde, o único que Ihe restara de seu país de origem era a língua, pois nada poderia substituir a língua materna (Gaus 1964). Esta dissociação entre povo, Estado e língua está, evidentemente, em choque com a concepção de Estado nacional moderno. Se Arendt tivesse percebido mais claramente a contradição entre liberdade individual e identidade nacional, constitutiva do Estado nacional liberal, talvez pudesse compreender melhor a tensão entre sua opção pessoal pela condição de pária e os compromissos e coerções políticas nacionais que a preocuparam ao longo de sua vida, e que fizeram da condição de apátrida uma anomalia inviável em um mundo de Estados nacionais (Stolcke 1995).

\section{Liberdade e ação política}

À análise histórica do totalitarismo de Arendt seguem-se, em rápida sucessão, três estudos de cunho político-teórico: A Condição Humana (1958b), Entre o Passado e o Presente (1968a [1961]) e Sobre a Revolução (1965), nos quais ela propõe uma renovação da filosofia política clássica com vistas a superar a noção genérica de natureza humana a ela subjacente, e elaborar uma forma de conciliar a liberdade e pluralidade individuais com a ação política em um mundo compartilhado. 
Em 1960, no entanto, o julgamento, em J erusalém, do tenente-coronel das SS, Adolf Eichmann, principal responsável por organizar o transporte dos judeus aos campos de extermínio, oferece a Arendt uma oportunidade inesperada para aproximar-se da realidade empírica dos campos de morte. Ela revisa sua concepção do crime que, na realidade, constituiu um "crime contra a humanidade" e propõe um Tribunal Penal Internacional para julgá-lo.

Arendt presenciou o julgamento como correspondente do The $\mathrm{New}$ Yorker. Em 1963, publica Eichmann em J erusalém, com o provocador subtítulo Um Estudo da Banalidade do Mal (Arendt 1986 [1963]). Este é o livro mais controvertido de toda a sua obra, no qual explica a escalada dos crimes cometidos pelo regime nacional-socialista, com especial atenção para sua dimensão moral. Se, em As Origens do Totalitarismo, Arendt havia visto nas "fábricas de extermínio" nazistas a manifestação do mal radical, agora, ela retrata Eichmann como a encarnação da banalização do mal. Sua tese da banalidade do mal causa espanto, pois em lugar de tratar o holocausto como um episódio isolado de irracionalidade, Arendt julga a humanidade enquanto tal. A ameaça personificada em Eichmann transcendia a singularidade política do Terceiro Reich, posto que suas condições de possibilidade residiam na própria sociedade moderna burocrática de massas, pela falta de empatia com o sofrimento alheio que propiciava um tipo de personalidade submissa à ordem estabelecida que gerou.

O julgamento de Eichmann não revelou nada de concretamente novo para além de evidenciar, mais uma vez, as monstruosas condições em que se deu o extermínio dos judeus europeus. Em sua análise da personalidade de Eichmann, Arendt fornece chaves perturbadoras mas imprescindíveis à compreensão da conduta daqueles que tornaram possível a "solução final". Nem seus executores foram monstros singulares, nem seus atos foram excepcionais na sociedade moderna. Longe de ter sido o resultado de um longo e sistemático planejamento político, a "solução final" consistiu, na verdade, em uma sucessão de acontecimentos em si triviais, singularmente difusos, automatizados e terrivelmente rotineiros que impediram qualquer reação significativa de índole moral. A desvinculação entre o executor e as vítimas do crime nada teve de anacrônico, nem de irracional. Arendt desafia a visão convencional sobre Eichmann como a quinta-essência diabólica do fanatismo ideológico anti-semita. $\mathrm{O}$ acusado exemplificava, pelo contrário, a terrível banalidade do mal, pois tinha cometido os crimes simplesmente por não pensar no que fazia, por “inconsciência". Eichmann tinha sido um burocrata subalterno medíocre, um funcionário de rotina, pedante e vaidoso, para quem virtudes subsidiárias 
como a obediência, a hierarquia e a ordem haviam se transformado em instrumentos do crime. $\mathrm{O}$ angustiante na personalidade de Eichmann é, precisamente, que ele, como muitos outros, longe de ser um sádico, fora inquietantemente normal. Em nenhum momento, Arendt pretendeu escamotear a responsabilidade do regime nacional-socialista, nem da população alemã pelos crimes cometidos, mas sim, compreender os efeitos psicológicos do emprego sistemático do terror por parte do regime totalitário quando suspende qualquer inibição moral entre seus executores e propicia, para além do sigilo oficial, toda uma série de justificativas falaciosas entre a população alemã, que invalidavam o significado moral dos atos7. Como Zygmunt Baumann concordaria mais tarde,

“O holocausto não foi simplesmente um problema judeu e, tampouco, um fato exclusivo à história judaica. O holocausto nasceu e foi executado em nossa sociedade racional moderna, em um ponto alto de nossa civilização, na culminação das conquistas culturais humanas, sendo, por essa razão, um problema dessa sociedade, civilização e cultura." (Baumann 1991:x)

Segundo Arendt, nem as vítimas da "solução final" podiam ser eximidas completamente da responsabilidade de sua própria destruição. Os consel hos judaicos tinham colaborado, em diferentes medidas, com nazistas como Eichmann na fatal ilusão de que lidavam com anti-semitas convencionais, influenciáveis e subornáveis, em lugar de perceber o novo dessa potente máquina da morte, um reconhecimento que teria exigido uma oposição política muito mais radical. Esta crítica de A rendt, que distingue os funcionários judeus e a população judia, tem seu contraponto na crítica à escassa e ambivalente oposição alemã contra Hitler.

A rendt concordou com a condenação de Eichmann à pena de morte. Visto que Eichmann não quisera compartilhar o mundo com os judeus, estes não tinham por que comparti-lo com ele. No entanto, ela teve sérias dúvidas em relação ao Tribunal de J erusalém, por ser, ao mesmo tempo, juiz e parte da causa julgada, e por interpretar o holocausto como um crime contra o povo judeu. A rendt rejeitava a tese de que existia uma continuidade na história judaica que reservava aos judeus o eterno papel de vítimas, assim como um destino singular, dado que esta tese acaba justificando, de modo indireto, o anti-semitismo. M ais do que um fato inerente à relação entre judeus e não-judeus, o extermínio dos judeus europeus constituía um "crime contra a humanidade cometido contra o povo judeu". As discriminações anti-semitas promulgadas pelas leis de N uremberg de 1935 criaram sim uma segregação de âmbito "nacional", mas quando o 
regime nazista coloca em prática sua política de expulsão e de aniquilamento dos judeus, surge um novo tipo de crime de alcance internacional. A expulsão de judeus alemães do território alemão infringia a soberania territorial dos Estados vizinhos. O extermínio constituía um crime contra a humanidade, na medida em que, pelo contrário, atentava contra a pluralidade, traço inerente à condição humana, sem o qual a espécie humana era inconcebível ${ }^{8}$. Como Arendt sustentaria de modo profético, se o extermínio dos judeus fosse entendido como um crime cometido contra um povo em particular, poderia converter-se em precedente de futuros genocídios (A rendt 1986:317-ss.). M as as autoridades de Israel não concordaram com o estabelecimento de um Tribunal Penal Internacional, nem o Tribunal de J erusalém pôde aceitar o holocausto como um "crime contra a humanidade". E Arendt não encontrou solução para o dilema que a "inconsciência" do acusado colocou para a justiça moderna, sempre atenta a fatores subjetivos.

Eichmann em J erusalém detonou uma avalanche de críticas. A ampla campanha de desautorização do livro significou um profundo corte na sua vida, levando-a a um profundo estado de solidão, do tipo que ela mesma já analisara, e que se instaura quando é negado a al guém o diálogo com outrem. Naquele momento, experimenta o que J aspers denominou de "risco do público", essa insegurança em que incorrem aqueles que defendem a liberdade de pensamento sem se apoiar em nenhum movimento político, nem confiar em nada além de seu próprio julgamento independente (Nordmann 1999:87).

A "controvérsia Eichmann" giraria, por um lado, em torno à aparente banalização da personalidade de Eichmann e, por outro, à negação, por parte de Arendt, da inocência dos próprios judeus. Os críticos não quiseram entender que, antes de tudo, Arendt queria compreender as condições extremas nas quais era possível liquidar seres humanos inocentes, sem que isto provocasse uma rebelião das consciências. Também não se interessaram pela sua reflexão acerca dos limites que a emergente sociedade burocrática de massas impunha ao julgamento individual e à ação política.

\section{0 que fazer?}

A pesar de sua íntima familiaridade com os horrores totalitários, Arendt não perde a esperança no ser humano. Inspirada em A Crítica do J uízo de Kant, segundo o qual "a força exterior que arranca do ser humano a liberdade de comunicar suas idéias em público, retira-Ihe também a liberdade de 
pensar" (Arendt 1994:216), Arendt optou pelo pensamento como dimensão da ação política (Arendt 1968a). A maior parte de seus escritos posteriores nasce do esforço para resgatar a possibilidade da liberdade de julgamento fundada na percepção de um mundo compartilhado. Suas reflexões sobre "o que é a política?" contêm outra tensão, já não mais histórica, mas de caráter teórico-político, inerente ao dilema posto pela modernidade sobre como conciliar a liberdade de pensamento do indivíduo com o fato social da condição humana e da ação política. A rendt não anula, nem se esquiva deste dilema, ainda que não consiga resolvê-lo (Birulés 1997:38).

À terrível "inconsciência" dos verdugos nazistas, a esse agnosticismo moral gerado pelo desenraizamento do ser humano e ausência de laços sociais compartilhados, à perda do compromisso com o público na sociedade moderna de massas, que tornam o indivíduo extraordinariamente vulnerável a manipulações totalitárias, A rendt contrapõe a condição de pária como requisito do julgamento individual e da recuperação de uma cultura cívica do público. A essência das ditaduras totalitárias consiste, assim, na despolitização, no sentido da supressão da liberdade de pensamento, de vontade e de criação (Arendt 1994:204). Entretanto, é unicamente o julgamento individual, livre da tradição, de raízes familiares e da obediência às normas, que assegura a liberdade de movimento exigida pela agilidade que o enfrentamento de situações imprevistas requer, agilidade esta cuja ausência conduziu ao desastre do holocausto. O indivíduo é o ponto de referência irredutível dessa liberdade de movimento que Arendt reivindica quando rejeita os determinismos essencialistas e históricos (N ordmann 1993:88; 1999). Não se trata do livre-arbítrio postulado pelo individualismo liberal, mas da liberdade que coincide com a ação: "quando se está atuando, se é livre, não antes, nem depois" (Arendt 1994:206). Conforme assinala Birulés, ao assumir a contingência, não como deficiência, mas como uma forma positiva de ser, Arendt tenta distanciar-se tanto do sujeito moderno quanto de princípios transcendentes. No entanto, essa postura inconformista não significa submeter o pensamento ao mero acidente, mas sim implica a defesa decidida da responsabilidade em relação ao mundo (Birulés 1997:31-32). A rendt resiste às correntes filosóficas anglo-saxônicas do empirismo e do liberalismo. Postular a liberdade de pensamento não quer dizer descartar qualquer critério, e tampouco o acontecimento. Neste ponto, Arendt diferencia-se do pensamento pós-moderno, que dissolve a realidade em interpretações e construções discursivas (N ordmann 1999:72). Como escreve na apresentação de Entre Passado e Presente, " estes são experimentos no pensamento po- 
lítico, entendido como resultado da atual idade de acontecimentos políticos, e minha suposição é a de que o pensamento nasce dos acontecimentos da experiência viva e deve estar vinculado a eles como único guia que permite orientar-nos." (Arendt 1994:18)

A rendt apóia a experiência viva como fonte do pensamento e da ação política na antropologia. O poder de iniciativa, de começar al go novo no mundo, define a condição humana. Esta faculdade é por ela denominada de natalidade, aquilo que sempre introduz algo novo no mundo. É daí, portanto, que a condição humana, em vez de estar prefigurada por algum tipo de natureza humana genérica, caracteriza-se por uma pluralidade e liberdade originais. É a partir do fato da natalidade que o ser humano é introduzido ao mundo e pode adquirir uma multiplicidade de aparências através da palavra e da ação (Cruz 1999a:20). Desse modo, Arendt pluraliza o universal. Além disso, a ação política, diferenciada da simples ação requerida para sobreviver, define-se como tal somente se acompanhada da palavra, do discurso, que implica e gera redes de relações e inaugura uma cadeia de acontecimentos, cujo fim é, não obstante, sempre, imprevisível (Birulés 1997:18-19). É esse caráter da imprevisibilidade do devir histórico que exige a agilidade propiciada pela liberdade de movimento, condição do pensamento livre.

A Segunda Guerra M undial não foi sucedida por uma paz segura, mas pela Guerra Fria. A té os anos 60 , há em A rendt uma única referência direta ao pacifismo, no fim de As Origens do Totalitarismo, em que A rendt ironiza os pacifismos levianos e insiste que a única razão que poderia justificar uma guerra é o combate a condições - como os atrozes tormentos infligidos aos presos nos campos de concentração - que tornam a vida absolutamente insuportável (A rendt 1973:442). A sombra da bomba atômica e o avanço das técnicas bélicas modernas inauguraram o equilíbrio do terror entre os dois grandes blocos políticos em disputa pela partilha do planeta. Em artigos publicados no New York Review of Books, nos anos 60 e inícios dos 70, Arendt denunciou a intervenção militar dos Estados Unidos no Vietnã e os abusos imperialistas do poder presidencial. Simultaneamente, manifestou desprezo pelos miseráveis compromissos próprios à política eleitoral convencional, sendo muito crítica com a glorificação da violência nas doutrinas e projetos revolucionários. Encontrou, no entanto, inspiração política no movimento estudantil dos anos 60 e, em especial, no movimento não violento de desobediência civil, pois se aproximava mais de sua idéia de associação política voluntária e espontânea como forma de ação política para a livre expressão de reivindicações minoritárias (Arendt 1973). 
Em contraste, no âmbito internacional, Arendt antecipou com perspicácia as conseqüências destrutivas da ausência de um árbitro supranacional eficaz nos conflitos armados que fosse verdadeiramente independente. Como assinala, com a lucidez advinda de sua própria experiência, um árbitro e uma justiça universais são inviáveis enquanto os Estados exercerem poder em assuntos externos legitimados pelo manto da sua sacrossanta soberania nacional. Com certeza, pequenos avanços ocorreram com o princípio da extraterritorialidade de crimes cometidos contra a humanidade. Mas, enquanto o Estado nacional moderno não seja colocado em questão de forma radical, a situação será sempre essa, conquistas isoladas. Portanto, o pensamento inconformista de A rendt apresenta-se como uma fonte de inspiração excepcional para uma crítica humanista radical do mortífero mundo atual.

Recebido em 16 de jul ho de 2001

A provado em 6 de fevereiro de 2002

Tradução: Maria J osé Alfaro Freire

Verena Stolcke, formada pela Oxford University, é professora do Departamento de Historia de Sociedades Precapitalistas y Antropología Social da Universidad Autónoma de Barcelona. 


\section{Notas}

* Agradeço a Fina Birulés, profunda conhecedora da obra de Hannah Arendt, pela ajuda bibliográfica que me dispensou na elaboração deste texto.

1 Para aqueles que desejam familiarizar-se com o contexto social e político dessa crítica cultural do início do século XX, sugiro a leitura das autobiografias de alguns de seus autores. Destaque-se nessas autobiografias, a tragédia de ter uma belíssima língua, o alemão, cujo povo repudia e condena ao desterro (Benjamin 1987; Canetti 1994; 1998; Elias 1994; Freud e Zweig 2000).

2 À medida que o pensamento de Hannah Arendt foi sendo recuperado na década passada, surge um considerável número de textos biográficos e análises de sua obra. M enciono alguns, para aqueles que desejam aprofundar-se na relação entre sua trajetória pessoal e sua obra, bem como sobre outros aspectos desta última (Benhabib 1992; 1996; Birulés 1993; 1995; 2000; Birulés e Cruz 1994; Cruz 1999b; Young-Bruehl 1993; Wieviorka 2000; ver também Arendt 1968c; Canetti 1977). A relação que Arendt manteve com Heidegger deu margem a constantes críticas sobre sua incongruência política. Arendt estudou com ele entre 1924-25, quando tiveram, então, uma relação amorosa. Ainda que apoiando o regime nacional-socialista, este filósofo nunca deixou de ser, para ela, além de J aspers, o mais destacado filósofo alemão contemporâneo. Seu debate com a obra de Heidegger nunca foi interrompido, tendo tido com ele vários encontros no período pós-guerra (Arendt e Blumenfeld 1995:268).

3 Em 1926, Kurt Blumenfeld proferira uma palestra para a associação estudantil sionista de Heidelberg, convidado pelo filósofo Hans J onas. Hannah A rendt estava entre o público. A pesar das profundas diferenças de opinião sobre a solução para o problema judeu e sobre a fundação de um Estado judeu, a amizade entre Arendt e Blumenfeld perdurou até a morte deste (Arendt e Blumenfeld 1995:52, 285).

4 Quando se exila, Arendt deixa a salvo uma cópia do manuscrito da biografia de Varnhagen com seu primo Ernst Fürst, em J erusalém, e outra com sua amiga íntima Anne Mandelsohn-Weil, em Paris. No entanto, o livro foi publicado somente em 1958, em uma versão inglesa (Arendt 1958a), e em 1959, em alemão (A rendt 1959). A rendt foi, algumas vezes, recriminada pelo não comprometimento de seus escritos de teoria política com a condição específica das mulheres, assim como pela sua postura crítica em face do movimento feminista. Tanto a biografia de Varnhagen, quanto seu texto biográfico sobre Rosa Luxemburgo, revelam, no entanto, uma inegável identificação com o destino das mulheres que se expuseram na sociedade e na política (Benhabib 1993; A rendt 1968b). O seu desinteresse pelo movimento feminista pode ser entendido como outra manifestação de sua defesa incondicional da liberdade de pensamento e de suas reservas perante as organizações políticas. 
5 Nos primeiros anos, A rendt escreveu para várias revistas judaicas como J ewish Frontier, Aufbau, (Reconstrução), Commentary, M enorah J ournal, construindo um nome como ensaísta política. Advogava, por exemplo, por um exército judeu, ainda que tivesse a esperança de que, no futuro, judeus e palestinos pudessem viver juntos em um Estado pal estino. M ais tarde, publicou também na Partisan Review. Foi diretora da editora judaico-alemã Schocken Books e divulgou os diários de Franz Kafka, bem como a obra de Bernard Lazare. Terminada a guerra, ela assumiu a direção da organização J ewish Cultural Reconstruction.

6 A seguir, utilizo também a cuidadosa leitura que o historiador alemão Hans M ommsen faz na sua introdução à edição de 1986 do relatório do julgamento de Eichmann, em J erusalém (M ommsen 1986:9-48).

7 As memórias que Adolf Eichmann escreveu na prisão em Israel durante os meses do julgamento, que acabam de ser publicadas, documentam este fato de modo perturbador (Tertsch 2000:6).

8 Entre aqueles que solicitaram que Eichmann fosse julgado por um Tribunal Penal Internacional, o único que concordou com A rendt em que “o crime contra os judeus era simultaneamente um crime contra a humanidade" foi Karl J aspers.

\section{Referências bibliográficas}

ARENDT, Hannah. 1953. “Understanding and Politics". Perspectives USA, 4. .1958a. The Life of a J ewess. London: s/e.

. 1958b. The Human Condition. Chicago: Chicago University Press (em espanhol La Condición Humana, Barcelona, Paidós Ibérica, 1998).

. 1959. Rahel Varnhagen. Lebensgeschichte einer deutschen J üdin aus der Romantik. M unich: Piper (em espanhol Vida de una M ujer J udía, Barcelona, Lumen, 2000).

.1965. On Revolution. New York: The Viking Press (em espanhol Sobre la Revolución, Madrid, Alianza, 1988).
1967 [1951]. The Origins of Totalitarianism. New York: A Harvest/HBJ Book (em espanhol Los Orígenes del Totalitarismo (2 vols.), Barcelona, Planeta-Agostini, 1994).

. 1968a [1961]. Between Past and Present. New York: The Viking Press (em alemão Zwischen Vergangenheit und Zukunft, Munich, R. Piper GmbH \& Cvo., KG, 1994). . 1968b. “Rosa Luxemburg 18711919". In: Men in Dark Times. New York: Harcourt, Brace \& World, Inc. (em espanhol Hombres en Tiempos de Oscuridad, Barcelona, Gedisa Editorial, 1989).

. 1968c. “Introduction: Walter Ben- 
jamin: 1892-1940". In: W. Benjamin, Illuminations. New York: Harcourt, Brace \& World, Inc.

. 1973. Crisis de la República. Madrid: Taurus Ediciones, S.A.

. 1986 [1963]. Eichmann in J erusalem. Ein Bericht von der Banalität des Bösen. M unich: Piper Verlag GmbH. .1993. Besuch in Deutschland. Hamburgo: Rotbuch Verlag. . 1994. Hannah A rendt. Zwischen Vergangenheit und Zukunft. Übungen im politischen Denken I. Munich: Piper Verlag (em espanhol Entre el Pasado y el Futuro. Ocho Ejercicios sobre la Reflexión Política, Barcelona, Península). . 1999. Rede anlässlich der Verleihung des Lessingpreises 1959. Hamburgo: Europäische Verlagsanstalt. e BLUMENFELD, Kurt. 1995. “... in keinem Besitz verwurzelt". Hamburgo: Rotbuch Verlag.

BAUMANN, Zygmunt. 1991. Modernity and the Holocaust. Cambridge: Polity Press.

BENHABIB, Seyla. 1992. Situating the Self. Cambridge: Polity Press.

_ . 1993. “La Paria y su Sombra: Sobre la Invisibilidad de las M ujeres en la Filosofía Política de Hannah Arendt". Revista Internacional de Filosofía Política, 2, novembro. . 1996. El Reluctante Modernismo de Hannah Arendt. El Diálogo con Martin Heidegger. Valencia: Episteme.

BENJ AM IN, Walter. 1987. Berliner Kindheit um neunzehnhundert. Frankfurt: Suhrkamp Verlag.

. 2000. Gesammelte Briefe. Band VI, 1938-1940 (editado por Christoph Gödde e Henri Lonitz). Frankfurt: Suhrkamp Verlag.

BIRULÉS, Fina. 1993. Hannah Arendt ¿Qué Es la Política? (comp. e introd.). Barcelona: Ediciones Paidós/ICEUAB.
. 1995. La Especificidad de lo Político: Hannah Arendt. Valencia: Episteme.

. 1997. “La Pasión por Comprender". Archipiélago, 30.

(comp.). 2000. Hannah Arendt. El Orgullo de Pensar. Barcelona: Gedisa Editorial.

e CRUZ, Manuel (comps.). 1994. En Torno a Hannah Arendt. Madrid: Centro de Estudios Constitucionales. CANETTI, Elias. 1977. Die gerette Zunge. Geschichte eienr J ugend. Frankfurt: Fischer Taschenbuch Verlag. . 1994. Das Augenspiel. Lebensgeschichte 1931-1937. Frankfurt: Fischer Taschenbuch Verlag. . 1998. Die Fackel im Ohr. Lebensgeschichte 1921-1931. Frankfurt: Fischer Taschenbuch Verlag.

CRUZ, Manuel. 1999a. Hannah Arendt. De la Historia a la Acción (comp. e introd.). Barcelona: Ediciones Paidós/ ICE-UAB.

. 1999b. Entre Amigas. Correspondencia entre Hannah Arendt y Mary M cCarthy. Barcelona: Lumen.

ELIAS, N orbert. 1994. Conocimiento y Poder. Madrid: Las Ediciones de la Piqueta (em especial, o prólogo de J ulia Varela).

FREUD, Sigmund e ZWEIG, Arnold. 2000. Correspondencia 1927-1939. BarceIona: Gedisa Editorial.

GAUS, Günter. 1964. Zur Person. Porträts in Frage und Antwort. Munich: Feder Verlag (em catalão, “N omés em Queda la Llengua Materna. Conversa amb Hannah Arendt", Saber, 13, primavera de 1987).

KLEM PERER, Victor. 1995. I ch will Zeugnis ablegen bis zum letzten. Tagebücher 1933-1945. Berlin: AufbauVerlag, 2 vols.

MOMMSEN, Hans. 1986.“Hannah Arendt und der Prozess gegen Adolf Eichmann". In: H. A rendt, Eichmann in 
J erusalem. Ein Bericht von der Banalität des Bösen. Munich: Piper Verlag $\mathrm{GmbH}$.

NORDMANN, Ingeborg. 1993. “Erfahrungen in einem Land, das die Realität verloren hat". In: H. A rendt, Besuch in Deutschland. Hamburgo: Rotbuch Verlag.

. 1999. "A uf Freiheit kommt es an". In: H. Arendt, Rede anlässlich der Verleihung des Lessingpreises 1959. Hamburgo: Europäische Verlagsanstalt.

STOLCKE, Verena. 1995. “New Rhetorics of Exclusion in Europe". Current Anthropology, 36, fevereiro.

TERTSCH, Hermann. 2000. “El 'Relojero' del Holocausto. Las Memorias de Adolf Eichmann Revelan el Alma Rutinaria y M inuciosa de uno de los Mayores Criminales Nazis". El País, 5 de março.

WHITFIELD, Stephen J . 1998. “Hannah Arendt. 1906-1975".

WIEVIORKA, Annette. 2000. Auschwitz Explicat a la M eva Filla. Barcelona: Portic Temes.

YOUNG-BRUEHL, Elisabeth. 1993. Hannah Arendt. Valencia: Edicions Alfons el Magnánim. 
Resumo

Cada teoria tem sua biografia. A obra de Hannah A rendt sobre o totalitarismo nasceu de suas vivências como judia alemã, desterrada de seu próprio país. Em seu pensamento inconformista, ocupa um lugar central a noção de pária, que inspira uma filosofia política na qual busca conciliar liberdade intelectual e compromisso político. Subjacente a esta filosofia, encontra-se uma antropologia humanista cujo núcleo é uma concepção da experiência humana compartilhada cuja diversidade reside precisamente em uma liberdade criativa originária. Ela desafia assim as fronteiras e identidades exclusivas, fruto do Estado nacional moderno, e propõe em seu lugar uma cultura cívica e uma justiça que transcendam os marcos nacionais.

Palavras-chave Hanna Arendt, Nacionalismo, Autoritarismo, Totalitarismo
Every theory has its own biography. Hannah Arendt's work on totalitarianism was born from her experiences as a German J ew, exiled from her own country. Central to her nonconformist thought is the notion of pariah, inspiring a political philosophy in which she seeks to reconcile intellectual freedom with political commitment. Behind this philosophy lies a humanist anthropology whose nucleus is a conception of shared human experience, the diversity of which resides precisely in an original creative freedom. As a result, her work challenges exclusive identities and borders - products of the modern nation state - and in place proposes a civic culture and a form of justice transcending national limits. Key w ords Hanna Arendt, Nationalism, Authoritarianism, Totalitarianism 